\title{
Social Work Licensure: Implications for Strengthening Social Work Practice in Egypt
}

\author{
Elaine Jurkowski, PhD, \\ School of Social Work, \\ Southern Illinois University Carbondale, Quigley
}




\section{ABSTRACT}

One of the hallmarks or essential attributes of a profession has been defined as licensure (Greenwood, 2002). This paper will use a case study approach using specific state examples from Canada and the United States to display how licensure can affect the social work profession in Egypt. An analysis of specific state based legislation related to licensure suggests that licensure has strengthened a profession's professional identity, improved the respect garnered from other professions relative to multidisciplinary collaboration and led to opportunities for privatization and private practice. This paper will also articulate some of the steps required in the licensure process from legislation to the development of oversight from a state based or national Department of Professional Regulation. Lastly the paper will outline some of the potential impacts for social work as a profession and how the social work profession can mature in Egypt as a result of licensure.

Key words: social work, licensure

Social work in practice dates back many centuries, and can coin its beginnings to the charity movements within various countries, often spearheaded by one's religious belief systems and the notion of charity. In the European and North American Contexts, for example, social work is known to have been rooted in the Elizabethan Poor Laws (De Scweinitz,). Originally, charity within the European context was perceived to be a responsibility and sign of one's own piety. Charity was in the form of direct relief (money, food etc.). However, with the notion of feudalism coming to an end, the poor were considered to be a direct threat to social order, and thus an organized system of care emerged to care for these individuals, which led rise to the Elizabethan Poor Laws in England (Wikopedia, 2008).

Thus, while the concept of taking care of those in need, and the practice of taking care of the poor is rooted in all major world religions, the practice and professionalism of social work is a relatively new concept ( $19^{\text {th }}$ Century) and has been legitimated by a professional set of guidelines and specific strategies to govern its practice. These guidelines help shape the profession of social work, and help legitimate its practice within the profession and also in collaboration with other professions. Such guidelines include specific 
attributes for the profession, and often include some oversight form an independent source, found through licensure.

Is social work a profession in Egypt? What attributes lead to one's definition of social work as a profession? Is this profession legitimate within the eyes of only fellow colleagues who are social workers, or are we seen as active members of an interdisciplinary team that would include medicine, pharmacy, nurses and a variety of allied health professionals? What are some of the hallmarks of licensure and can licensure strengthen social work practice in Egypt? These are questions, which will be raised in this paper, addressed, and a plan of action will be proposed as a result of this inquiry.

\section{Attributes of a Profession}

Some of the most prolific writing about the debate involving the attributes of a profession have been authored by Ernest Greenwood. His early work has addressed the attributes of a profession, and this still holds true, some fifty years later. Greenwood (1957) defined attributes of a profession to include:

- A systematic body of knowledge

- Professional authority and credibility

- Regulation and control of its members

- A professional code of ethics; and

- A culture of values, norms and symbols.

Within many professions, the attributes are prominent. Professions such as medicine, dentistry, nursing and social work all share a systematic body of knowledge, which fuel the profession's practice. Social work, for example was based upon a systematic body of knowledge about the individual/casework, group work, community work and social policy. Although there are many specific fields of practice, all use the same systematic approaches incorporating micro; meso and macro practice issues and include content related to five core content areas. These areas such as Human Behavior and the Social Environment, Social Work Practice, research methods, social policy and fieldwork, all create a systematic body of knowledge for our profession.

Physicians have maintained their professional authority and credibility through their professional associations and through their stance/presence, established through longstanding relationships and legitimization as a profession. Similarly, we see other professional 
groups establish themselves in like manner such as nurses, teachers, pharmacists etc.

As professions such as medicine has grown over time, the regulation and control of its members has also been important, to maintain the integrity of the profession. Regulatory bodies monitor the professional practice, and assure against malpractice or incompetence within the profession. These are essential features of any professional body such as medicine. When malpractice or incompetence have been cited, such as in the case of medicine, the professional association, and or Regulatory body (ie: Department of Professional Regulation) come into play, hear complaints and assure that concerns raised to do affect the health and safety of consumers, and assure a standard practice of care. In settings where social work as a profession, has been legitimized (licensed) such as Canada and the United States, this same practice is true, and members professional practice is regulated and monitored.

A "Code of Ethics" serves as a cornerstone for professions such as medicine, nursing, pharmacy and dentistry. Social workers in North America are also guided by codes of ethics. In the United States, The National Association of Social Workers (NASW) has developed a code of ethics for its members to be followed as a standard for social work practice. Similarly, Canadian social workers have a code of ethics, defined by the Canadian Association of Social Work (CASW). While there are similar features to each code of ethics, they are also dramatically different in some ways, as an effort to reflect the unique cultures and values that each country may possess, relative to the practice of the profession. The code of ethics, however serves as a cornerstone for guiding principles of the profession.

A dominant culture of social justice prevails within our profession of social work, regardless of one's country of origin. Within this culture, though, there are nuances, which can be defined by the specific culture within which one works. However, we would be remiss if we did not acknowledge that a culture for professional practice does exist within the social work practice, and in many contexts, this "professionalism" has been the basis for regulation.

\section{Perceptions and Definitions of Professionalism}

Professionalism takes on a variety of definitions and perceptions, however most have some common threads run through. These threads 
are threads of excellence and legitimization. Merriam-Webster's dictionary defines professionalism as a "set of attitudes and behaviors believed to be appropriate to a particular occupation". Other definitions of professionalism have included "the active demonstration of traits of a profession" (APHA, 2000), or "those attitudes and behavior that serve to maintain patient interest above [physician] selfinterest" (American Board of Internal Medicine, 1965) and "displaying values, beliefs and attitudes that put the needs of another above your personal needs" (Beardsley, 1996). In addition, attitudes of professionals were described by Hammer (2000) to include:

- The use of a professional organization and colleagues as a major source of professional ideas and judgments about practice.

- The belief in service to the public and that one's professional practice is indispensable to society and will benefit the public.

- The belief in self-regulation, and that one's peers are the best qualified to judge one's work.

- The calling to the field through a dedication to the field, despite or regardless of extrinsic rewards.

- Autonomy (one can make independent decisions without external pressure from clients, non-professionals and employers); and

- Unique relationships with clients.

These definitions of professionalism, although originally drafted for professions of medicine, nursing and pharmacy are applicable to social work as a profession. These same definitions form the cornerstone of these professions regulatory nature (ie licensure). Given the nature of these professions, and the manner in which these professions are legitimated, if social work wants to be considered a legitimate profession, it may be worthy of considering how to regulate the profession, through licensure or registration.

\section{Models of Social Work Regulation and Control - Licensure versus Registration}

Two specific models for Social Work regulation and control exist, and are both used in Canada and the United States. Registration and licensure are both specific to the profession, and require similar expectations. In the United States, the norm appears to be licensure, 


\section{Egyptian Journal of Social Work (EJSW) http://ejsw.journals.ekb.eg \\ Print ISSN: 2356-9204 Online ISSN: 2356-9212 Vol 1, Issue 1, June 2015}

while in Canada the norm appears to be "professional registration". Both approaches require legislation and professional oversight through a governmental entity, which regulates and monitors the profession. The main difference is one of perception. In cultures, which require legitimization, licensure may be necessary however, a registration process can also accomplish the same goals for professionalization mentioned earlier in this paper. In many states and provinces, registration was used as an initial step toward the licensure process. After social work was recognized as a professional entity, states with registration moved toward licensure.

Legislation is generally state based. In Canada, each province sets its own standards for regulation or licensure, and similarly, in the United States, each state will outline their own specific legislation and administrative code for practice.

In both models, licensure or registration, specific language and expectations for the profession have been crafted in both the legislation and "administrative code" (administrative code are the "rules" which implement the legislation). Some of these components include:

- Provisions for "grandfathering" in other professionals not trained in social work.

- Procedures for the application of licensure.

- Professional experiences required for licensure

- Approved Colleges, Universities and Graduate Schools of Social Work.

- Fees

- Examinations

- Continuing education requirements

- The renewal process

- Unethical, unauthorized and unprofessional conduct guidelines

- Guidelines for independent practice of clinical social work

- Guidelines for professional experience.

\section{The Road to Legitimization in Egypt...to be licensed or to not be licensed?}

This now begs the argument for social work as a profession in Egypt. Should we or should we not be licensed? What are the costs to the profession and what would be the benefits to the profession? 
Firstly, if in fact, social workers are practicing in a manner that embodies the attributes of the profession outlined at the outset of this paper, then the next step is to display how we are a profession to other professionals. The benefit can only enhance our professional identify and improve our ability to be recognized as a profession. This recognition can also bring to bear monetary benefits, because once recognized governmental and third parties will pay for services. Social workers also become a part of an active treatment team in the helping professions. Social work as a profession also moves beyond the act of charity, to one of a professional social change agent.

They are costs associated with both licensure and nonlicensure. As a profession, licensure will force the profession to develop professional standards, a professional code of ethic or code of conduct, and practice expectations, which will involve some depth and rigor. This will safeguard both the professional and consumer. In this process, social work will also gain a professional distinction, which can lead to equal partnership with other helping professionals (medicine, nursing etc.) and part of a multidisciplinary collaborative process. Individuals will also be responsible for all fees associated with the process of becoming registered or licensed. While many may be remunerated poorly at the current time, this process may also help to improve the salaries and working conditions of social work professionals. In addition, it can push governmental entities to support social work professionals to be employed in key helping roles within governmental social service portfolios.

Costs involved with non-licensure or registration can include a demoralization of the profession, diffusion of activities and the impact of social work interventions. Individuals carrying out the title of "social worker" without the values or attributes of the profession will also continue to practice, if no regulation is in place. Incompetence on the part of such practitioners can cause damage or harm to individuals, families and/or communities, and can mar the professional integrity and public understanding of social work as a profession. Such practice can also seriously impact the social health of communities and the legitimacy of the profession. Another cost to the profession is that social work will have a difficult time being autonomous, and nonlicensure closes the door to private, independent social work practice as a option. 
Egyptian Journal of Social Work (EJSW) http://ejsw.journals.ekb.eg

Print ISSN: 2356-9204 Online ISSN: 2356-9212 Vol 1, Issue 1, June 2015

\section{Licensure in Egypt: A Blueprint for progress toward this goal}

Licensure in Egypt can become a reality if we in fact take some specific steps towards this goal. These steps can include a blueprint with the following:

- Identify individual stakeholders who embrace the social work profession, both within and outside the profession, who can be persuasive with colleagues.

- Begin a grassroots movement to educate colleagues on the attributes of the profession, steps in the process toward licensures and costs/of inaction.

- Build upon the current code of ethics to include principles which will regulate the practice of the social work profession (Both the United States and Canada have examples which can be used).

- Build a strong nucleus of individuals who will serve as a backbone for both national and state/province oriented leadership as part of a National Association of Social Workers.

- Develop draft legislation and administrative rules, which can be introduced into state legislatures for either registration or licensure.

- Identify and court politicians who will introduce legislation into your legislature and navigate the bills through the political process until these become law.

- Develop curriculum within Schools of Social Work to support a standard of practice that would be consistent with standards and attributes of a professional quality for social work.

- Establish licensing requirements, which can then be Board Certified and approved.

\section{Summary}

In summary, to be, or not to be.... A social legitimate social work profession is the question. This paper have provided an overview of the attributes of a profession, how social work can be strengthened as a profession through licensure and the pros and cons for licensure. The implications for social work practice in Egypt have been laid out and articulated. We, as social workers came into the profession because we wanted to make a difference and we wanted to 
be change agents. We also want to assure that safe professional standards of practice exist within our profession of social work. Why should we limit ourselves now, by limiting our potential without licensure? The only limit to the profession will be the limit we place upon ourselves. Can we as a practice justify not pursuing licensure?

\section{References}

225 ILCS 20/ (2008). Clinical Social Work and Social Work Practice Act. State of Illinois.

APHA (2000). Pharmacy student professionalism. Journal of American Pharmacy Association. 40. 96-102.

American Board of Internal Medicine. (1995). Project Professionalization. ABIM Committee on the Evaluation of Professional Competence. Philadelphia, PA.

Association of Social Work Boards (2008). Licensing Requirements. Association of Social Work Boards. Retrieved from http://www.aswb.org.lic_req.html.

Beardsley, R.S. (1996). Enhancing professionalism in pharmacy education and practice. American Journal of Pharmacy Education.60.26s-28s.

Greenwood, E. (1957). Attributes of a profession. Social Work, 2(July) 44-57.

Hammer, D.P. (2000). Professional attitudes and behaviors: The A's and B's of Professionalism. American Journal of Pharmaceutical Education, 64 (Winter). 456-465.

Joint Committee on Administrative Rules (2008) Administrative Code, Part 1470 Clinical Social Worker and Social Work Practice Act. Retrieved from

http:www.ilga.gov/commission/jcar/admincode/068, January 24, 2008.

National Association of Social Workers (2008).

Straus, G., (1963). Professionalism and occupational associations. Industrial Relations. II(3) 8-9.

Wikipedia, (2008). Social Work. Retrieved from http://en.wikopedia.org/wiki/social_services on January 24, 2008.

Wilensky, H.L. (1964). The professionalization of everyone. American Sociological Review. 33.137-146. 